IZA DP No. 4691

How Changes in Unemployment Benefit Duration Affect the Inflow into Unemployment

Jan C. van Ours

Sander Tuit

January 2010 


\title{
How Changes in Unemployment Benefit Duration Affect the Inflow into Unemployment
}

\author{
Jan C. van Ours \\ CentER, Tilburg University, \\ University of Melbourne, CEPR and IZA \\ Sander Tuit \\ CentER, Tilburg University
}
Discussion Paper No. 4691
January 2010

\author{
IZA \\ P.O. Box 7240 \\ 53072 Bonn \\ Germany \\ Phone: +49-228-3894-0 \\ Fax: +49-228-3894-180 \\ E-mail: iza@iza.org
}

Any opinions expressed here are those of the author(s) and not those of IZA. Research published in this series may include views on policy, but the institute itself takes no institutional policy positions.

The Institute for the Study of Labor (IZA) in Bonn is a local and virtual international research center and a place of communication between science, politics and business. IZA is an independent nonprofit organization supported by Deutsche Post Foundation. The center is associated with the University of Bonn and offers a stimulating research environment through its international network, workshops and conferences, data service, project support, research visits and doctoral program. IZA engages in (i) original and internationally competitive research in all fields of labor economics, (ii) development of policy concepts, and (iii) dissemination of research results and concepts to the interested public.

IZA Discussion Papers often represent preliminary work and are circulated to encourage discussion. Citation of such a paper should account for its provisional character. A revised version may be available directly from the author. 
IZA Discussion Paper No. 4691

January 2010

\section{ABSTRACT \\ How Changes in Unemployment Benefit Duration Affect the Inflow into Unemployment}

We study how changes in the maximum benefit duration affect the inflow into unemployment in the Netherlands. Until August 2003, workers who became unemployed after age 57.5 were entitled to unemployment benefits until the age of 65 , after which they would receive old age pensions. This characteristic made it attractive for workers to enter unemployment shortly after age 57.5 rather than shortly before. Indeed, we find a peak in the inflow into unemployment for workers after age 57.5. From August 2003 onwards the maximum benefit durations were reduced. We find that shortly after 2003 the peak in the inflow disappeared.

JEL Classification: H55, J64, J65

Keywords: unemployment insurance, potential benefit duration, unemployment inflow

Corresponding author:

Jan C. van Ours

CentER

Tilburg University

P.O. Box 90153

5000 LE Tilburg

The Netherlands

E-mail: vanours@uvt.nl 


\section{Introduction}

Empirical research on the effects of unemployment insurance (UI) usually focuses on potential outflow effects. High levels and long durations of unemployment benefits provide little incentives for unemployed workers to find a job quickly. Therefore, unemployment durations increase with both the level and the duration of the unemployment benefits. However, unemployment benefits may also affect the inflow into unemployment. If the level of benefits goes up or the maximum benefit duration increases it may be more attractive for workers to enter unemployment and collect unemployment benefits.

The focus of this paper is on the unemployment inflow effects of a reduction of the maximum unemployment benefit duration in The Netherlands. Until August 2003, if workers became unemployed after age 57.5 they were entitled to unemployment benefits until the age of 65 , after which they would receive old age pensions. This characteristic made it attractive for workers to enter unemployment shortly after they became 57.5 rather than shortly before. From August 2003 onwards the maximum benefit durations were reduced. This reduction removed the incentive for workers to enter unemployment shortly after age 57.5 rather than before that age. The policy change gives us the opportunity to investigate the effects of the incentives that influence inflow into unemployment. We find that until August 2003 there was an age-specific spike in the inflow into unemployment. This spike slowly disappeared after August 2003. Apparently workers have some influence on the timing of their unemployment spell and when possible they use this influence to their advantage.

The paper is set-up as follows. In section 2 we present a brief overview of previous studies on the relationship between the duration of UI benefits and inflow into unemployment. Section 3 describes the main characteristics of the Dutch UI system and the data we use in our analysis. Section 4 presents our parameter estimates and section 5 concludes. 


\section{Previous studies}

Empirical studies on the unemployment inflow effect of the maximum benefit duration are rare. Most of the inflow studies focus on requirements concerning entrance into unemployment insurance. Christofides and McKenna (1995) and Christofides and McKenna (1996) for example find a clear relationship between entrance requirements of Canadian UI and employment durations. The exit rate from employment to unemployment increases substantially as soon as the workers satisfy the number of weeks worked in order to qualify for UI benefits. Andersen and Meyer (1997) investigate the take up rate of unemployment benefit insurance of workers separating from their employer. They find that both the level and the maximum duration of benefits have a significant positive effect. Green and Riddell (1997) study the effect of changes on entrance requirements on the inflow into Canadian unemployment finding that changes in entrance requirements have a significant impact on employment durations. They also find that many employment spells that just qualify under the old system are extended to just qualify under the new system. And they find that all of the response is in layoffs, not quits, which suggest that employers play an important role in the adjustment of employment durations. Green and Sargent (1998) analyze Canadian data and also find evidence of concentrations of job spell durations at the entrance requirement point and at the point at which individuals have qualified for the maximum possible weeks of UI receipts. Winter-Ebmer (2003) also looks at Austria around 1990 and finds an increase in the inflow into unemployment of older workers after an increase in the potential benefit duration. These Austrian older workers face incentives similar to those faced by the Dutch older workers. The very generous increase also allowed for them to move into unemployment as an early retirement paid by the state. This is also confirmed by Lalive and Zweimuller (2003). They find even that the effects are particulary strong around the end of the duration of the extension program. Finally, Lalive et al. (2006) also study the Austrian situation, where there was an increase in the potential benefit duration for some 
groups of unemployed workers. One of those groups is workers aged above 50. They show that the induced increase in the steady-state unemployment rate is caused mostly by an increase in the inflow into unemployment.

\section{Dutch unemployment insurance}

\subsection{Characteristic of the system}

In the Netherlands, workers are entitled to UI benefits if they become involuntarily unemployed and lose their earnings for at least 5 or half of their working hours. They must have been employed for at least 26 consecutive weeks out of the 39 weeks prior to unemployment (26 out of 39 weeks condition). Excluded from UI-benefits are individuals who receive fulltime disability benefits or have reached the age of 65 . Benefits end when individuals are no longer unemployed or reach the maximum benefit duration. The potential benefit duration (PBD) and the benefit level depend on the type of UI-benefits that can be collected. Individuals may be eligible for short term benefits, wage dependent benefits or extended benefits. Eligibility for these three benefit types depends on labor experience and the age at which the individual becomes unemployed.

If an unemployed individual meets the 26 out of 39 weeks condition and has also received wages for at least 52 days in the 4 calendar years during the 5 years prior to unemployment (4 out of 5 years condition), he or she qualifies for wage dependent benefits. These benefits last for at least 6 months and are extended with 3 months to 4.5 years, depending on labor experience. Labor experience is calculated as the number of years in the 5 calendar years prior to unemployment in which the individual has received wages for at least 52 days, plus the number of calendar years between the year that the individual turned 18 and the 5 years prior to unemployment. As a result of the 4 out of 5 years condition, the PBD for wage related benefits depends almost completely on the age at which the individual becomes unemployed.

All individuals who started to receive wage related UI-benefits before 
August 11, 2003, were also entitled to extended benefits. For the duration of extended benefits, age was the only criterion. For individuals who became unemployed before the age of $57 \frac{1}{2}$, this duration was equal to 2 years, for older individuals extended benefits would last up to 3.5 years. So, there was a clear age-related discontinuity with a maximum benefit duration of 6 years for workers who became unemployed shortly before turning $57 \frac{1}{2}$ and a maximum benefit duration of 7.5 years for workers who became unemployed shortly after turning $57 \frac{1}{2}$. Therefore, workers who became unemployed from age $57 \frac{1}{2}$ onwards would therefore receive UI-benefits until the standard retirement age of 65 . Thus, UI-benefits have in the past been used as retirement pathway (see Heyma, 2001).

On August 11, 2003 extended benefits were abolished. Therefore, the age-related discontinuity in maximum benefit duration disappeared. Irrespective of workers became unemployed shortly before or shortly after age $57 \frac{1}{2}$ maximum unemployment benefits would be 4 years. Workers who would become unemployed after age $57 \frac{1}{2}$ would no longer be entitled to receive unemployment benefits until age 65 . This would imply that before becoming entitled to pension benefits these workers would have to rely on means-tested welfare benefits. The abolishment of the extended benefits was announced over the weekend and gave employers and workers no time to react to the change in incentive structure.

\subsection{Our data}

Our dataset is provided by Statistics Netherlands (CBS) and concerns administrative information from municipalities and the organization that is responsible for the payment of unemployment benefits (UWV). The dataset contains all unemployment spells that started in the calendar years 20012005. For the empirical analysis we only use the unemployment spells of workers aged between 55 and 59. Furthermore, we only use the inflow of male workers since the number of female workers becoming unemployed in this age category is rather small. 
Figure 1 presents the inflow into unemployment for 2001-02 and for 2005, the first two years and the last year in our sample. As shown in 2001-02 there is a big spike in inflow into unemployment for workers aged just above $57 \frac{1}{2}$. In terms of separation rate the level is about $1.7 \%$ before the inflow spike, whereas in the inflow spike the separation rate doubles to $3.4 \%$. In 2005, when the age-related discontinuity in maximum benefit duration was no longer present there is no clear inflow spike at age $57 \frac{1}{2}$.

Fig. 1: Inflow into unemployment by age; 2001-02 \& 2005

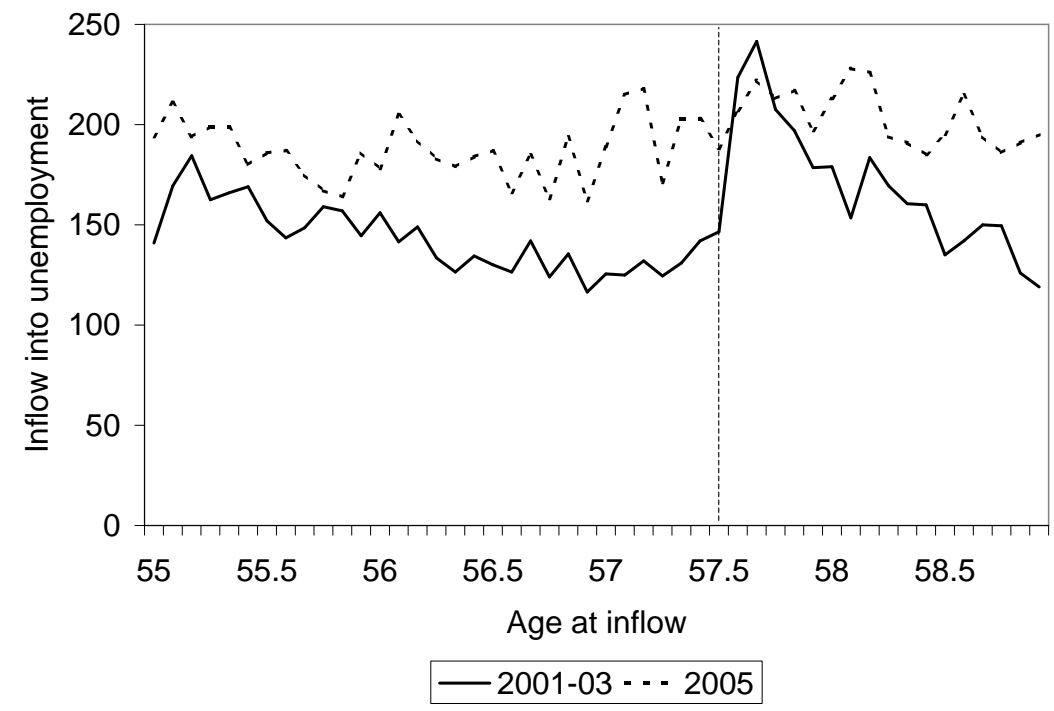

\section{Empirical analysis}

\subsection{Inflow into unemployment}

Our dependent variable is the logarithm of the number of workers $y$ in a monthly age category $\tau$ who enter unemployment in a particular calendar 
month $t$ :

$\log y_{t, \tau}=\alpha_{t}+\beta \tau+\left(\delta_{1} d_{57.0-5}+\delta_{2} d_{57.6-11}\right) B_{t}+\left(\delta_{3} d_{57.0-5}+\delta_{4} d_{57.6-11}\right)\left(1-B_{t}\right)+\epsilon_{t, \tau}$

where the $\alpha_{t}(t=2,3, \ldots, 60)$ are calendar-month fixed effects, $\tau(1,3, \ldots, 48)$ is an age trend in months from 1 at age 55 and 48 at age 58 and 11 months, $d_{57.0-5}\left(d_{57.6-11}\right)$ is a dummy variable if the age at inflow is between 57 and $57 \frac{1}{2}$ ( $57 \frac{1}{2}$ and 58$)$, and $B$ is a dummy variable which is 1 when the date of inflow into unemployment was before January 1, 2004. Furthermore, the $\delta$ 's are parameters and $\epsilon_{t, \tau}$ is an error term that is assumed to be distributed i.i.d.

The equation above tests whether there has been a shift in inflow, whether workers are postponing their unemployment for (at least) a couple of months. However, it may not be the case that workers influence the timing of their unemployment by postponing their dismissal, but avoiding their unemployment altogether. Therefore, we also estimate a restricted model imposing $\delta_{1}=\delta_{3}=0$.

Since the change in maximum benefit durations can unexpected we can analyze its effects as if the change was a natural experiment. Therefore, we can estimate both equations using OLS. The relevant parameter estimates are presented in the first row of Table 1. As shown, before the change in the benefit entitlement rules the inflow into unemployment in the 6 months before age $57 \frac{1}{2}$ is $4.5 \%$ lower, while in the 6 months thereafter it is $28.8 \%$ higher. This suggests that part of the inflow spike is due to a shift from the inflow shortly before age $57 \frac{1}{2}$ to shortly thereafter. After January 1, 2004 the inflow changed a lot. Now, shortly before age $57 \frac{1}{2}$ as well as shortly thereafter there is a higher inflow. Focussing on the post $57 \frac{1}{2}$ inflow spike in the reduced model, we see that it was reduced from $29.4 \%$ before January 1, 2004 to $18.3 \%$ after January 1, 2004.

Rows 2-4 of Table 1 show the parameter estimates if we use different points in time to indicate the change in potential benefit duration. Basically, the pre benefit-change spike is not very much affected by the timing of 
Tab. 1: Parameter estimates inflow into unemployment

\begin{tabular}{|c|c|c|c|c|c|c|}
\hline & \multicolumn{4}{|c|}{ Full model } & \multicolumn{2}{|c|}{ Reduced model } \\
\hline & \multicolumn{2}{|c|}{ Before } & \multicolumn{2}{|c|}{ After } & \multirow{2}{*}{$\begin{array}{c}\text { Before } \\
57.6-58\left(\delta_{3}\right)\end{array}$} & \multirow{2}{*}{$\begin{array}{c}\text { After } \\
57.6-58\left(\delta_{4}\right)\end{array}$} \\
\hline & $57-57.5\left(\delta_{1}\right)$ & $57.6-58\left(\delta_{3}\right)$ & $57-57.5\left(\delta_{2}\right)$ & $57.6-58\left(\delta_{4}\right)$ & & \\
\hline \multirow[t]{2}{*}{ Break January 2004} & $-0.045^{* * *}$ & $0.288^{* * *}$ & $0.105^{* * *}$ & $0.199^{* * *}$ & $0.294^{* * *}$ & $0.183^{* * *}$ \\
\hline & $(0.024)$ & $(0.025)$ & $(0.030)$ & $(0.031)$ & $(0.024)$ & $(0.030)$ \\
\hline \multicolumn{7}{|l|}{ Alternative breaks: } \\
\hline \multirow[t]{2}{*}{ September 2003} & $-0.073^{* * *}$ & $0.297^{* * *}$ & $0.117^{* * *}$ & $0.200^{* * *}$ & $0.307^{* * *}$ & $0.183^{* * *}$ \\
\hline & $(0.025)$ & $(0.003)$ & $(0.028)$ & $(0.028)$ & $(0.026)$ & $(0.028)$ \\
\hline \multirow[t]{2}{*}{ May 2004} & $-0.025^{* * *}$ & $0.294^{* * *}$ & $0.009^{* * *}$ & $0.167^{* * *}$ & $0.297^{* * *}$ & $0.153^{* * *}$ \\
\hline & $(0.023)$ & $(0.002)$ & $(0.033)$ & $(0.034)$ & $(0.023)$ & $(0.033)$ \\
\hline \multirow[t]{2}{*}{ January 2005} & -0.006 & $0.279^{* * *}$ & $0.095^{* *}$ & $0.140^{* * *}$ & $0.298^{* * *}$ & $0.126^{* * *}$ \\
\hline & $(0.021)$ & $(0.021)$ & $(0.043)$ & $(0.044)$ & $(0.021)$ & $(0.044)$ \\
\hline Without the period & $-0.081^{* * *}$ & $0.280^{* * *}$ & $0.074^{* *}$ & $0.132^{* * *}$ & $0.295^{* * *}$ & $0.122^{* * *}$ \\
\hline September 2003-August 2004 & $(0.025)$ & $(0.026)$ & $(0.035)$ & $(0.036)$ & $(0.026)$ & $(0.035)$ \\
\hline
\end{tabular}

the break, while the post benefit-change spike becomes smaller the later the timing of the break. Apparently, workers and employers needed some calendar time to adjust their behavior to the new benefit rules.

The bottom row of Table 1 shows the parameter estimates if we ignore 1 year of observations, from September 2003 - August 2004. Again, the pre benefit-change spike is substantial while the post benefit-change spike is substantially smaller. Additional sensitivity analyses are presented in Appendix B.

\subsection{Characteristics of the inflow}

Clearly, the reduction of the maximum benefit duration had an effect on the inflow of workers aged just above 57.5. Apparently, workers have some influence on the timing of becoming unemployed. To investigate whether some workers are more influential than other workers we study the composition of the inflow in terms of personal characteristics. ${ }^{1}$

Table 7 presents the mean values of the personal characteristics distin-

\footnotetext{
${ }^{1}$ Appendix A provides definitions and information concerning the personal characteristics.
} 
guished by age of inflow. As shown the income of the workers gradually increases with the age of entrance, but this happens both before and after the reduction in maximum benefit duration. Similarly the percentage of workers being married increases with age, while the percentages of singles and workers having children that live with them decline with age. The other personal characteristics are not much correlated with the age of inflow into unemployment.

Tab. 2: Characteristics inflow by age of entrance

\begin{tabular}{|c|c|c|c|c|c|c|c|c|}
\hline \multirow[b]{2}{*}{ Age } & \multicolumn{8}{|c|}{ Before January 2004} \\
\hline & $55-55.5$ & $55.5-56$ & $56-56.5$ & $56.5-57$ & $57-57.5$ & $57.5-58$ & $58-58.5$ & $58.5-59$ \\
\hline Earnings (1000) & 9.8 & 9.8 & 9.9 & 10.2 & 10.5 & 11.7 & 11.9 & 12.1 \\
\hline Weekly hours & 35.9 & 35.4 & 35.5 & 35.6 & 35.6 & 35.7 & 35.5 & 35.5 \\
\hline Married (\%) & 75.4 & 76.8 & 76.8 & 77.7 & 76.6 & 80.2 & 82.0 & 82.4 \\
\hline Dutch (\%) & 93.1 & 93.3 & 93.4 & 94.0 & 93.2 & 94.4 & 93.0 & 94.3 \\
\hline Single (\%) & 16.1 & 15.0 & 13.8 & 13.6 & 14.3 & 11.8 & 11.6 & 11.5 \\
\hline Children (\%) & 42.7 & 39.7 & 37.9 & 35.0 & 32.7 & 30.5 & 29.3 & 28.4 \\
\hline \multicolumn{9}{|c|}{ Education level (\%) } \\
\hline 1 & 12.8 & 11.7 & 12.8 & 12.5 & 13.9 & 14.6 & 15.6 & 14.0 \\
\hline 2 & 26.6 & 25.8 & 26.5 & 27.8 & 26.9 & 29.4 & 28.6 & 29.1 \\
\hline 3 & 33.4 & 34.8 & 36.5 & 34.6 & 34.1 & 32.8 & 31.6 & 31.1 \\
\hline 4 & 16.0 & 16.1 & 14.3 & 15.1 & 15.6 & 13.8 & 14.2 & 16.0 \\
\hline \multirow[t]{2}{*}{5} & 5.4 & 5.3 & 4.2 & 5.0 & 4.5 & 4.3 & 4.3 & 4.2 \\
\hline & \multicolumn{8}{|c|}{ After January 2004} \\
\hline Age & $55-55.5$ & $55.5-56$ & $56-56.5$ & $56.5-57$ & $57-57.5$ & $57.5-58$ & $58-58.5$ & $58.5-59$ \\
\hline Earnings (1000) & 10.1 & 10.2 & 10.2 & 10.1 & 10.5 & 11.5 & 10.3 & 10.0 \\
\hline Weekly hours & 35.4 & 35.5 & 35.6 & 35.6 & 35.5 & 35.8 & 35.5 & 35.7 \\
\hline Married (\%) & 75.3 & 75.4 & 76.9 & 78.4 & 76.5 & 79.9 & 79.4 & 79.0 \\
\hline Dutch (\%) & 91.3 & 92.4 & 92.8 & 92.7 & 93.1 & 94.5 & 94.6 & 93.9 \\
\hline Single (\%) & 15.8 & 16.1 & 13.3 & 13.7 & 15.8 & 13.8 & 13.7 & 13.6 \\
\hline Children (\%) & 45.5 & 43.4 & 40.9 & 41.4 & 36.9 & 33.3 & 31.3 & 30.2 \\
\hline \multicolumn{9}{|c|}{ Education level (\%) } \\
\hline 1 & 11.5 & 11.5 & 11.7 & 10.4 & 13.0 & 11.9 & 12.3 & 12.7 \\
\hline 2 & 22.8 & 24.1 & 25.1 & 25.2 & 25.2 & 25.0 & 26.9 & 26.5 \\
\hline 3 & 39.8 & 39.5 & 38.7 & 40.5 & 38.2 & 39.4 & 38.9 & 37.1 \\
\hline 4 & 15.8 & 16.0 & 15.8 & 15.8 & 15.2 & 15.5 & 14.1 & 15.6 \\
\hline 5 & 7.0 & 6.1 & 6.2 & 5.1 & 5.6 & 5.3 & 5.1 & 4.9 \\
\hline
\end{tabular}


To investigate whether indeed the characteristics of individuals who enter unemployment shortly after age 57.5 are not different from other unemployed we performed regressions using equation (1), replacing the dependent variable by averages of inflow characteristics. The parameter estimates are presented in Table 3. As shown only income is clearly correlated with the inflow spike. While before the reduction in maximum benefit duration the income of workers aged 57.5-58 at the time of inflow was higher than for other workers, this effect is gone after the reduction in maximum benefits. Apparently, especially high wage workers were able to postpone being dismissed until an age at which they could expected to be eligible for benefits until age 65.

Tab. 3: Parameter estimates characteristics of the inflow

\begin{tabular}{lcccrrr} 
& \multicolumn{2}{c}{ Before } & \multicolumn{2}{c}{ After } & Before & \multicolumn{1}{c}{ After } \\
& $\delta_{1}$ & $\delta_{3}$ & $\delta_{2}$ & $\delta_{4}$ & $\delta 3$ & $\delta 4$ \\
$\log$ (Earnings) & $-0.0351^{*}$ & $0.0970^{* * *}$ & -0.0073 & -0.0096 & $0.0055^{* * *}$ & -0.0073 \\
& $(0.0174)$ & $(0.0178)$ & $(0.0316)$ & $(0.0319)$ & $(0.0004)$ & $(0.0315)$ \\
Weekly hours & -0.0776 & 0.1514 & 0.0243 & 0.2328 & 0.1523 & 0.2292 \\
& $(0.1431)$ & $(0.1461)$ & $(0.1810)$ & $(0.1834)$ & $(0.1440)$ & $(0.1810)$ \\
Married & $-0.0285^{* * *}$ & -0.0002 & $-0.0234^{* *}$ & 0.0071 & 0.0051 & 0.0116 \\
& $(0.0087)$ & $(0.0088)$ & $(0.0110)$ & $(0.0111)$ & $(0.0087)$ & $(0.0110)$ \\
Single & -0.0022 & 0.0040 & 0.0069 & 0.0074 & 0.0042 & 0.0064 \\
& $(0.0053)$ & $(0.0054)$ & $(0.0067)$ & $(0.0068)$ & $(0.0053)$ & $(0.0067)$ \\
Single & 0.0113 & -0.0076 & $0.0189^{* *}$ & -0.0032 & -0.0098 & -0.0065 \\
& $(0.0070)$ & $(0.0072)$ & $(0.0089)$ & $(0.0090)$ & $(0.0071)$ & $(0.0089)$ \\
Children & -0.0035 & -0.0068 & 0.0051 & -0.0001 & -0.0063 & -0.0009 \\
& $(0.0989)$ & $(0.0101)$ & $(-0.0125)$ & $(0.0201)$ & $(0.0099)$ & $(0.0125)$ \\
Higher educated & 0.0001 & -0.0109 & 0.0040 & -0.0000 & -0.0109 & -0.0006 \\
(Education level $\geq 4)$ & $(0.0083)$ & $(0.0084)$ & $(0.0104)$ & $(0.0106)$ & $(0.0083)$ & $(0.0104)$ \\
Significance level: *** 99\% & & & & & &
\end{tabular}

\section{Conclusions}

In The Netherlands, extreme long benefit durations after age 57.5 provided incentives for workers to enter unemployment after that age and consequently receive benefits until age 65 . When this incentive that allowed 
workers to 'retire early' was abolished in August 2003, the age-specific inflow spike disappeared gradually. Apparently, workers had some influence on the timing of their unemployment spell and when possible they use this influence to their advantage. Especially high wage workers were able to exploit the characteristics of the unemployment benefit system.

We can only speculate about the mechanism through which the worker can influence the date at which he is fired. Workers put in effort in their job and are fired when their effort is below a certain minimum. Or workers are fired when there is a downturn in a firm's business. There are two types of arguments that can explain the spike in the inflow into unemployment. First, from a firm's perspective it may become less costly to fire a worker shortly after age 57.5 rather than shortly before, since the worker may not have an incentive to fight the dismissal as hard as when the worker does not have a possibility to retire with unemployment benefits. The worker can for instance promise to refrain from going to court to fight the dismissal in exchange for the employer promising to wait with firing the worker until he turns 57.5. And second it is possible that the effort level of the worker becomes lower when the worker has reached age 57.5 because unemployment becomes a more attractive labor market state. All in all, it is clear that workers have been using the unemployment benefit system to their advantage. 


\section{References}

Andersen, P. M. and Meyer, B. D.: 1997, Unemployment insurance take-up rates and the after-tax value of benefits, Quarterly Journal of Economics 112, 913-937.

Christofides, L. M. and McKenna, C. J.: 1995, Unemployment insurance and moral hazard in employment, Economics Letters 49, 205-210.

Christofides, L. M. and McKenna, C. J.: 1996, Unemployment insurance and job duration in canada, Journal of Labor Economics 14, 286312.

Green, D. A. and Riddell, W. C.: 1997, Qualifying for unemployment insurance: An empirical analysis, Economic Journal 107, 67-84.

Green, D. A. and Sargent, T. C.: 1998, Unemployment insurance and job durations: seasonal and non-seasonal jobs, Canadian Journal of Economics 31, 247-278.

Lalive, R., Van Ours, J. C. and Zweimuller, J.: 2006, How changes in potential benefit duration affect equilibrium unemployment, CentER Discussion Paper Series .

Lalive, R. and Zweimuller, J.: 2003, Benefit entitlement and the labor market: Evidence from a large-scale policy change, Labor Market Institutions and Public Policy .

Winter-Ebmer, R.: 2003, Benefit duration and unemployment entry: A quasi-experiment in austria, European Economic Review 47, 259-273. 


\section{Appendix A: Definitions of personal characteristics}

Table 4 gives an overview of the personal characteristics used in the analysis.

Tab. 4: Definitions of personal characteristics

$\begin{array}{lllll}\text { Variable } & \text { Contains } & \text { Min } & \text { Max } & \text { Mean } \\ \text { Earnings } & \text { Annual earnings (Euros) } & 1 & 149736 & 10650 \\ \text { Weekly hours } & \text { Number of weekly working hours prior to } & 1 & 80 & 34.56 \\ & \text { unemployment } & 0 & 1 & 0.78 \\ \text { Married } & 1 \text { if worker is married } & 0 & 1 & 0.93 \\ \text { Dutch } & 1 \text { if worker has only Dutch nationality } & & \\ \text { Single } & 1 \text { if worker is in a one person household } & 0 & 1 & 0.14 \\ \text { Children } & 1 \text { if there are children in the worker's } & 0 & 1 & 0.34 \\ & \text { household } & & & \\ \text { Education level 1 } & \text { Primary school } & 0 & 1 & 0.13 \\ \text { Education level 2 } & \text { Lower vocational education } & 0 & 1 & 0.27 \\ \text { Education level 3 } & \text { Middle vocational education/secondary } & 0 & 1 & 0.36 \\ & \text { school } & & & \\ \text { Education level 4 } & \text { Higher vocational education/Bachelor } & 0 & 1 & 0.15 \\ \text { Education level 5 } & \text { Master } & 0 & 1 & 0.05\end{array}$

\section{Appendix B: Additional sensitivity analysis}

\section{B-1 Age fixed effects}

By way of sensitivity analysis we replaced the age trend term in equation

(1) by age fixed effects:

$$
\log y_{t, \tau}=\alpha_{t}+\beta_{\tau}+\delta_{\tau}\left(1-B_{t}\right)+\epsilon_{t, \tau}
$$

where the $\beta_{\tau}(\tau=2,3, \ldots, 48)$ are age category fixed effects. The $\beta$ parameters show the relative inflow into unemployment before January 2004. The $\delta$ parameters show the difference between before and after the reduction of the benefit duration.

Without incentive effects, we would expect that, if labor productivity does not significantly change between the ages 55 and 59 , the $\beta$ parameter were negative if at all significant. When more workers retire, the population that is at risk of being fired decreases. Furthermore, if the abolishment of 
the extended benefits would have no effect, then the $\delta$ parameters should be insignificantly different from zero.

Table 5 and 6 presents all parameter estimates. The $\beta$ parameters increase just after the age of 57.5. The parameters of interest are significantly different from zero, while the parameters just before 57.5 and after 57.9, are usually insignificantly different from 0 . The fact that the spike partly disappears is shown in the $\delta$-estimates. These parameters are significantly different from zero where the pre-change spike is largest. However, when we test whether the spike completely disappears, the parameters combined are still significant.

In the top graph of Figure 2 we show the regression parameters in the following way. The $\beta$ parameters show the inflow before January 2004. The sum of the $\beta$ and $\delta$ parameters present the situation after January 2004.

When we take a look at the graph, we see that there are two interesting things going on with workers around the age of 57.5. Before January 2004 there is clearly a spike in unemployment inflow for workers just after the age of 57.5. We see that the spike has mostly disappeared after January 2004.

The bottom graph of Figure 2 plots the parameter estimates if we remove one year of observations from the sample. Basically, the results are almost identical to the ones in the top graph.

\section{B2 Inflow elasticity}

Our analysis uses a natural experiment driven change in an age-related discontinuity in maximum unemployment benefit duration. Without further assumptions the policy change does not allow us to establish an inflow elasticity of the maximum benefit duration, i.e. the percentage reduction in the inflow into unemployment due to the reduction in potential benefit duration. The change in age-specific inflow over time is influenced by changes in the maximum benefit duration but also by changes in the state of the labor market. To give an idea about the potential size of the inflow elasticity we 
estimated the following relationship:

$$
\log y_{t, \tau}=\beta_{0}+\beta_{1} u_{t}+\beta_{2} \log T_{t, \tau}+\beta_{3} t+\left(\delta_{1} d_{57.0-5}+\delta_{2} d_{57.6-11}\right) B_{t}+\epsilon_{t, \tau}
$$

where $u_{t}$ is the national unemployment rate in calendar month $t$ and $T_{t, \tau}$ is the maximum benefit duration in calendar month $t$ for age-of-inflow group $\tau$. The parameter $\beta_{1}$ measures the effect of the cycle on the inflow, $\beta_{2}$ in the inflow elasticity of benefit duration and $\beta_{3}$ represent a calendar time trend. The parameter estimates are presented in Table ??. As expected the economic cycle represented by the national unemployment rate has a significant positive effect on the unemployment inflow. There is also a negative calendar time trend affecting the inflow into unemployment. Without the time trend the effect of the unemployment rate is bigger, showing that the unemployment rate has a trend-like development over the period of our analysis.

The main parameter of interest, the inflow elasticity with respect to maximum benefit duration is significantly different from zero with a value of approximately $0.40-0.45$. 
Tab. 5: Full list of $\alpha$ parameters for the January 2004 estimation

\begin{tabular}{lrrl|lrrr} 
Var & Coef & SE & Sig & Var & Coef & SE & Sig \\
$\alpha_{2}$ & 0.072 & 0.0658 & & $\alpha_{32}$ & 0.167 & 0.0658 & $* *$ \\
$\alpha_{3}$ & 0.133 & 0.0658 & $* *$ & $\alpha_{33}$ & 0.416 & 0.0658 & $* * *$ \\
$\alpha_{4}$ & -0.272 & 0.0658 & $* * *$ & $\alpha_{34}$ & 0.593 & 0.0658 & $* * *$ \\
$\alpha_{5}$ & -0.015 & 0.0658 & & $\alpha_{35}$ & 0.429 & 0.0658 & $* * *$ \\
$\alpha_{6}$ & -0.304 & 0.0658 & $* * *$ & $\alpha_{36}$ & 0.382 & 0.0658 & $* * *$ \\
$\alpha_{7}$ & -0.200 & 0.0658 & $* * *$ & $\alpha_{37}$ & 0.619 & 0.0658 & $* * *$ \\
$\alpha_{8}$ & -0.253 & 0.0658 & $* * *$ & $\alpha_{38}$ & 0.449 & 0.1073 & $* * *$ \\
$\alpha_{9}$ & -0.389 & 0.0658 & $* * *$ & $\alpha_{39}$ & 0.405 & 0.1073 & $* * *$ \\
$\alpha_{10}$ & -0.197 & 0.0658 & $* * *$ & $\alpha_{40}$ & 0.560 & 0.1073 & $* * *$ \\
$\alpha_{11}$ & -0.017 & 0.0658 & & $\alpha_{41}$ & 0.128 & 0.1073 & \\
$\alpha_{12}$ & -0.537 & 0.0658 & $* * *$ & $\alpha_{42}$ & 0.386 & 0.1073 & $* * *$ \\
$\alpha_{13}$ & 0.576 & 0.0658 & $* * *$ & $\alpha_{43}$ & 0.612 & 0.1073 & $* * *$ \\
$\alpha_{14}$ & 0.153 & 0.0658 & $* *$ & $\alpha_{44}$ & 0.042 & 0.1073 & \\
$\alpha_{15}$ & 0.100 & 0.0658 & & $\alpha_{45}$ & 0.251 & 0.1073 & $* *$ \\
$\alpha_{16}$ & 0.137 & 0.0658 & $* *$ & $\alpha_{46}$ & 0.488 & 0.1073 & $* * *$ \\
$\alpha_{17}$ & 0.206 & 0.0658 & $* * *$ & $\alpha_{47}$ & 0.243 & 0.1073 & $* *$ \\
$\alpha_{18}$ & -0.048 & 0.0658 & & $\alpha_{48}$ & 0.598 & 0.1073 & $* * *$ \\
$\alpha_{19}$ & 0.051 & 0.0658 & & $\alpha_{49}$ & 0.638 & 0.1073 & $* * *$ \\
$\alpha_{20}$ & 0.164 & 0.0658 & $* *$ & $\alpha_{50}$ & 0.498 & 0.1073 & $* * *$ \\
$\alpha_{21}$ & 0.013 & 0.0658 & & $\alpha_{51}$ & 0.643 & 0.1073 & $* * *$ \\
$\alpha_{22}$ & 0.344 & 0.0658 & $* * *$ & $\alpha_{52}$ & 0.429 & 0.1073 & $* * *$ \\
$\alpha_{23}$ & 0.147 & 0.0658 & $* *$ & $\alpha_{53}$ & 0.110 & 0.1073 & \\
$\alpha_{24}$ & -0.099 & 0.0658 & & $\alpha_{54}$ & 0.387 & 0.1073 & $* * *$ \\
$\alpha_{25}$ & 0.720 & 0.0658 & $* * *$ & $\alpha_{55}$ & 0.050 & 0.1073 & \\
$\alpha_{26}$ & 0.373 & 0.0658 & $* * *$ & $\alpha_{56}$ & -0.020 & 0.1073 & \\
$\alpha_{27}$ & 0.278 & 0.0658 & $* * *$ & $\alpha_{57}$ & 0.265 & 0.1073 & $* *$ \\
$\alpha_{28}$ & 0.220 & 0.0658 & $* * *$ & $\alpha_{58}$ & 0.022 & 0.1073 & \\
$\alpha_{29}$ & 0.507 & 0.0658 & $* * *$ & $\alpha_{59}$ & 0.007 & 0.1073 & \\
$\alpha_{30}$ & 0.170 & 0.0658 & $* *$ & $\alpha_{60}$ & 0.474 & 0.1073 & $* * *$ \\
$\alpha_{31}$ & 0.514 & 0.0658 & $* * *$ & & & & \\
& & & & & & &
\end{tabular}


Tab. 6: Full list of $\beta$ and $\delta$ parameters for the January 2004 estimation

\begin{tabular}{|c|c|c|c|c|c|c|c|}
\hline Var & Coef & SE & Sig & Var & Coef & SE & Sig \\
\hline$\beta_{2}$ & 0.158 & 0.0749 & $* *$ & $\delta_{2}$ & -0.045 & 0.1210 & \\
\hline$\beta_{3}$ & 0.247 & 0.0749 & $* * *$ & $\delta_{3}$ & -0.156 & 0.1210 & \\
\hline$\beta_{4}$ & 0.130 & 0.0749 & $*$ & $\delta_{4}$ & -0.061 & 0.1210 & \\
\hline$\beta_{5}$ & 0.200 & 0.0749 & $* * *$ & $\delta_{5}$ & -0.095 & 0.1210 & \\
\hline$\beta_{6}$ & 0.135 & 0.0749 & $*$ & $\delta_{6}$ & -0.139 & 0.1210 & \\
\hline$\beta_{7}$ & 0.064 & 0.0749 & & $\delta_{7}$ & -0.037 & 0.1210 & \\
\hline$\beta_{8}$ & 0.005 & 0.0749 & & $\delta_{8}$ & -0.045 & 0.1210 & \\
\hline$\beta_{9}$ & 0.068 & 0.0749 & & $\delta_{9}$ & -0.135 & 0.1210 & \\
\hline$\beta_{10}$ & 0.095 & 0.0749 & & $\delta_{10}$ & -0.099 & 0.1210 & \\
\hline$\beta_{11}$ & 0.070 & 0.0749 & & $\delta_{11}$ & -0.183 & 0.1210 & \\
\hline$\beta_{12}$ & 0.045 & 0.0749 & & $\delta_{12}$ & -0.041 & 0.1210 & \\
\hline$\beta_{13}$ & 0.088 & 0.0749 & & $\delta_{13}$ & -0.097 & 0.1210 & \\
\hline$\beta_{14}$ & 0.058 & 0.0749 & & $\delta_{14}$ & -0.006 & 0.1210 & \\
\hline$\beta_{15}$ & 0.070 & 0.0749 & & $\delta_{15}$ & -0.034 & 0.1210 & \\
\hline$\beta_{16}$ & 0.018 & 0.0749 & & $\delta_{16}$ & 0.021 & 0.1210 & \\
\hline$\beta_{17}$ & -0.027 & 0.0749 & & $\delta_{17}$ & 0.069 & 0.1210 & \\
\hline$\beta_{18}$ & 0.017 & 0.0749 & & $\delta_{18}$ & 0.013 & 0.1210 & \\
\hline$\beta_{19}$ & -0.053 & 0.0749 & & $\delta_{19}$ & 0.047 & 0.1210 & \\
\hline$\beta_{20}$ & 0.002 & 0.0749 & & $\delta_{20}$ & -0.025 & 0.1210 & \\
\hline$\beta_{21}$ & 0.103 & 0.0749 & & $\delta_{21}$ & -0.019 & 0.1210 & \\
\hline$\beta_{22}$ & -0.042 & 0.0749 & & $\delta_{22}$ & -0.047 & 0.1210 & \\
\hline$\beta_{23}$ & 0.037 & 0.0749 & & $\delta_{23}$ & 0.058 & 0.1210 & \\
\hline$\beta_{24}$ & -0.061 & 0.0749 & & $\delta_{24}$ & -0.073 & 0.1210 & \\
\hline$\beta_{25}$ & -0.023 & 0.0749 & & $\delta_{25}$ & 0.045 & 0.1210 & \\
\hline$\beta_{26}$ & -0.024 & 0.0749 & & $\delta_{26}$ & 0.157 & 0.1210 & \\
\hline$\beta_{27}$ & -0.022 & 0.0749 & & $\delta_{27}$ & 0.160 & 0.1210 & \\
\hline$\beta_{28}$ & -0.055 & 0.0749 & & $\delta_{28}$ & 0.071 & 0.1210 & \\
\hline$\beta_{29}$ & -0.047 & 0.0749 & & $\delta_{29}$ & 0.100 & 0.1210 & \\
\hline$\beta_{30}$ & 0.019 & 0.0749 & & $\delta_{30}$ & 0.105 & 0.1210 & \\
\hline$\beta_{31}$ & 0.026 & 0.0749 & & $\delta_{31}$ & 0.043 & 0.1210 & \\
\hline$\beta_{32}$ & 0.442 & 0.0749 & $* * *$ & $\delta_{32}$ & -0.276 & 0.1210 & \\
\hline$\beta_{33}$ & 0.516 & 0.0749 & $* * *$ & $\delta_{33}$ & -0.260 & 0.1210 & \\
\hline$\beta_{34}$ & 0.328 & 0.0749 & $* * *$ & $\delta_{34}$ & -0.194 & 0.1210 & \\
\hline$\beta_{35}$ & 0.243 & 0.0749 & $* * *$ & $\delta_{35}$ & -0.060 & 0.1210 & \\
\hline$\beta_{36}$ & 0.125 & 0.0749 & $*$ & $\delta_{36}$ & 0.035 & 0.1210 & \\
\hline$\beta_{37}$ & 0.140 & 0.0749 & $*$ & $\delta_{37}$ & -0.035 & 0.1210 & \\
\hline$\beta_{38}$ & 0.051 & 0.0749 & & $\delta_{38}$ & 0.168 & 0.1210 & \\
\hline$\beta_{39}$ & 0.181 & 0.0749 & $* *$ & $\delta_{39}$ & 0.007 & 0.1210 & \\
\hline$\beta_{40}$ & 0.147 & 0.0749 & $* *$ & $\delta_{40}$ & -0.100 & 0.1210 & \\
\hline$\beta_{41}$ & 0.087 & 0.0749 & & $\delta_{41}$ & -0.049 & 0.1210 & \\
\hline$\beta_{42}$ & 0.040 & 0.0749 & & $\delta_{42}$ & -0.062 & 0.1210 & \\
\hline$\beta_{43}$ & -0.049 & 0.0749 & & $\delta_{43}$ & -0.057 & 0.1210 & \\
\hline$\beta_{44}$ & 0.028 & 0.0749 & & $\delta_{44}$ & 0.007 & 0.1210 & \\
\hline$\beta_{45}$ & -0.044 & 0.0749 & & $\delta_{45}$ & -0.026 & 0.1210 & \\
\hline$\beta_{46}$ & 0.038 & 0.0749 & & $\delta_{46}$ & -0.256 & 0.1210 & \\
\hline$\beta_{47}$ & -0.117 & 0.0749 & & $\delta_{47}$ & -0.021 & 0.1210 & \\
\hline$\beta_{48}$ & -0.208 & 0.0749 & $* * *$ & $\delta_{48}$ & -0.073 & 0.1210 & \\
\hline constant & 2.391 & 0.0701 & $* * *$ & & & & \\
\hline
\end{tabular}


Tab. 7: Parameter estimates inflow elasticities

\begin{tabular}{l|ccccc}
\hline & $u_{t}$ & $T_{t, \tau}$ & $t$ & & \\
& $\beta_{1}$ & $\beta_{2}$ & $\beta_{3}$ & $\delta_{1}$ & $\delta_{2}$ \\
\hline a. Baseline & & & & & \\
(Break January 2004) & $0.350^{* * *}$ & $0.371^{* * *}$ & $-0.005^{* * *}$ & -0.031 & $0.230^{* * *}$ \\
& $(0.019)$ & $(0.058)$ & $(0.001)$ & $(0.028)$ & $(0.030)$ \\
& $0.294^{* * *}$ & $0.446^{* * *}$ & - & -0.021 & $0.228^{* * *}$ \\
& $(0.015)$ & $(0.056)$ & - & $(0.028)$ & $(0.030)$ \\
\hline Alternative breaks & & & & & \\
b. September 2003 & $0.349^{* * *}$ & $0.352^{* * *}$ & $-0.005^{* * *}$ & $-0.081^{* * *}$ & $0.235^{* * *}$ \\
& $(0.019)$ & $(0.059)$ & $(0.001)$ & $(0.030)$ & $(0.032)$ \\
& $0.290^{* * *}$ & $0.437^{* * *}$ & - & $-0.075^{* * *}$ & $0.225^{* * *}$ \\
& $(0.015)$ & $(0.057)$ & - & $(0.030)$ & $(0.032)$ \\
c. May 2004 & $0.344^{* * *}$ & $0.372^{* * *}$ & $-0.004^{* * *}$ & -0.010 & $0.243^{* * *}$ \\
& $(0.019)$ & $(0.057)$ & $(0.001)$ & $(0.027)$ & $(0.028)$ \\
& $0.292^{* * *}$ & $0.438^{* * *}$ & - & 0.002 & $0.247^{* * *}$ \\
d. January 2005 & $(0.014)$ & $(0.055)$ & - & $(0.027)$ & $(0.028)$ \\
& $0.340^{* * *}$ & $0.394^{* * *}$ & $-0.004^{* * *}$ & -0.008 & $0.216^{* * *}$ \\
& $(0.014)$ & $(0.057)$ & $(0.001)$ & $(0.025)$ & $(0.025)$ \\
e. Without the period & $0.291^{* * *}$ & $0.456^{* * *}$ & - & 0.005 & $0.222^{* * *}$ \\
Sept. 2003-August 2004 & $(0.014)$ & $(0.055)$ & - & $(0.024)$ & $(0.025)$ \\
& & & & & \\
& $0.320^{* * *}$ & $0.552^{* * *}$ & -0.001 & $-0.067^{* *}$ & $0.213^{* * *}$ \\
& $(0.022)$ & $(0.065)$ & $(0.001)$ & $(0.030)$ & $(0.032)$ \\
& $0.302^{* * *}$ & $0.586^{* * *}$ & - & $-0.065^{* *}$ & $0.209^{* * *}$ \\
& $(0.015)$ & $(0.059)$ & - & $(0.030)$ & $(0.032)$ \\
\hline
\end{tabular}


Fig. 2: Graph of parameter estimates - Before (black) and after (grey) January 2004

a. Full period January 2001-December 2005

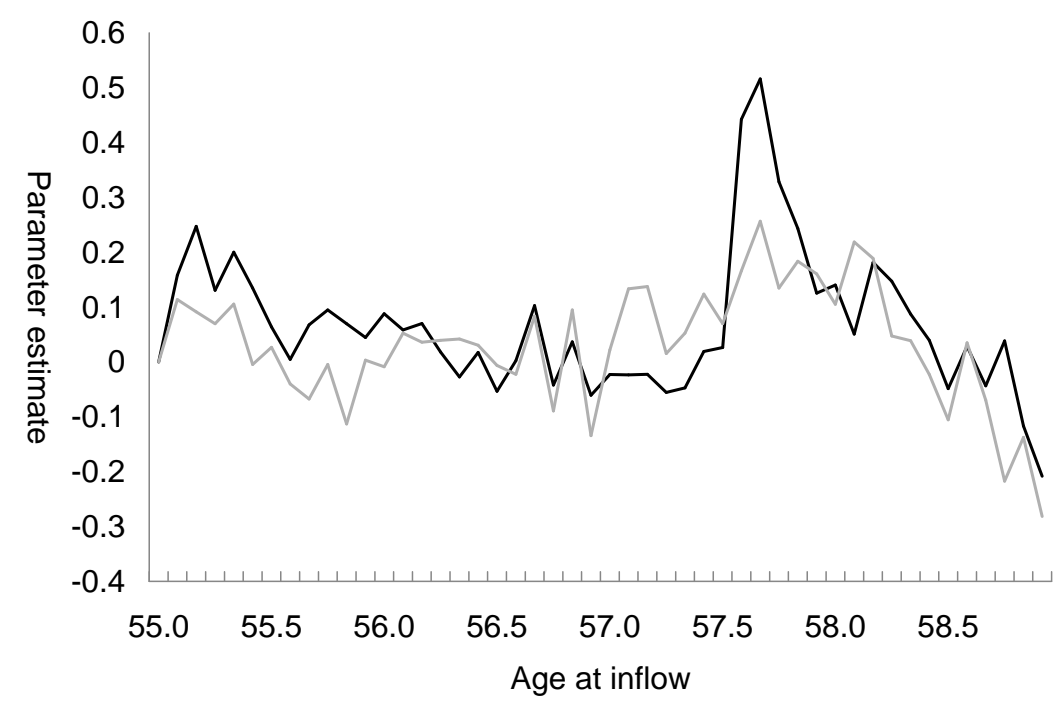

b. Without September 2003-August 2004

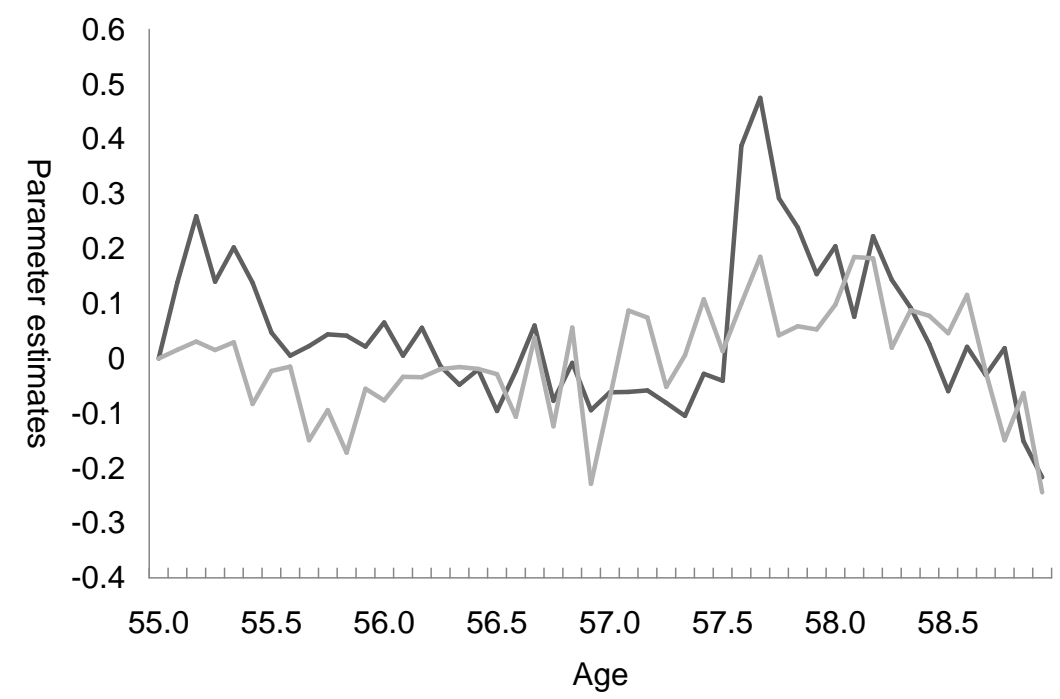

